\title{
Tensões e intenções: marcas de uma experiência de estesia no Ensino Superior
}

\author{
Tensiones e intenciones: marcas de una experiencia de estasis en la \\ enseñanza superior
}

Tensions and Intentions: Brands of a Higher Education Experience

\begin{abstract}
Jésica Hencke ${ }^{1}$
Resumo

$\mathrm{O}$ artigo que se desdobra apresenta uma dupla provocação: tensões aquilo que tenciona, que gera uma fricção e intenções ações com objetivos, interesses, ousadias e porque não desejos? Tem como objetivo provocar, através da língua escrita, rasgos de experiência vivida e formada pela sensação da estesia em uma turma de estudantes de Artes Visuais do Ensino Superior. A provocação foi criar um objeto gráfico-visual a partir do estudo do conceito de estesia em Picosque e Martins (2012) de forma a tornar compreensível este conceito e vivenciar um momento de experiência, como algo que nos passa e nos transforma, a partir dos estudos de Jorge Larrosa (2002). O desenvolvimento teórico-metodológico articula temas como corpo, sensação, estesia contrapondo-se a anestesia do mundo contemporâneo e experiência, relacionando-os com as produções gráfico-digitais através de uma a/r/tografia, de forma a promover processos de aprendizagem conceitual. Os objetos gráfico-visuais produzidos foram substrato para a compreensão da estesia, enquanto prática artística, que ecoa na aprendizagem dos estudantes sendo, um meio e não o fim de uma experiência vivencial.
\end{abstract}

Palavras-Chave: Estesia; Experiência; Ensino Superior; Corpo; Anestesia.

\section{Resumen}

El artículo que se desdobla presenta una doble provocación: tensiones aquello que piensa, que genera una fricción e intenciones acciones con objetivos, intereses, osadías y por qué no deseos? Tiene como objetivo provocar, a través de la lengua escrita, rasgos de experiencia vivida y formada por la sensación de la estasia en una clase de estudiantes de Artes Visuales de la Enseñanza Superior. La provocación fue crear un objeto gráficovisual a partir del estudio del concepto de estasia en Picosque y Martins (2012) para hacer comprensible este concepto y experimentar un momento de experiencia, como algo que nos pasa y nos transforma, estudios de Jorge Larrosa (2002). El desarrollo teórico-metodológico articula temas como cuerpo, sensación, estos se contraponen a la anestesia del mundo contemporáneo y la experiencia, relacionándolos con las producciones gráficas digitales a través de una a / r / tografía, para promover procesos de aprendizaje conceptual . Los objetos gráfico-visuales producidos fueron sustrato para la comprensión de la estasia, como práctica artística, que resuena en el aprendizaje de los estudiantes siendo, un medio y no el fin de una experiencia vivencial.

Palabras clave: Estasia; la experiencia; Enseñanza superior; Cuerpo; Anestesia.

\begin{abstract}
The article that unfolds presents a double provocation: tensions that think, that generates a friction and intentions actions with objectives, interests, daring and why not desires? Its objective is to provoke, through written language, features of lived experience and formed by the feeling of estesia in a class of Visual Arts students of Higher Education. The provocation was to create a graphic-visual object from the study of the concept of estesia in Picosque and Martins (2012) to make this concept understandable and experience a moment of experience, as something that happens to us and transforms us, Jorge Larrosas studies ( 2002). The theoretical-methodological development articulates subjects such as body, sensation, these are opposed to the anesthesia of the contemporary world and experience, relating them to the digital graphic productions through an a / $\mathrm{r} /$ tography,

\footnotetext{
${ }^{1}$ Mestre em Educação e Tecnologias pelo IFsul - Instituto Federal de Educação Sul-rio-grandense Campus Pelotas/RS. Mestre em Artes Visuais pela UFPEL - Universidade Federal de Pelotas; RS; Brasil; jesicahencke@gmail.com
} 
to promote conceptual learning processes. The graphic-visual objects produced were a substrate for the understanding of estesia, as an artistic practice that resonates in students' learning being a means and not the end of an experiential experience.

Keywords: Estesia; Experience; Higher education; Body; Anesthesia.

\section{Introdução}

Texto, poema, arte, expressões de um rasgo na prática pedagógica de uma professora artista e não de uma artista professora, uma experiência, a tentativa de ruir com a aridez do ensino superior e sua formalidade técnica-conceitual tornando-a expectativa, criação, vivência e evidência a partir do movimento mais banal e corriqueiro do ato de ensinar: a leitura e discussão de um texto com o intento de apropriar-se de um conceito, neste caso: estesia.

O texto é de Mirian Celeste Martins e Gisa Picosque (2012) "Revelações do corpo: estesia e conhecimento", o objetivo da aula era discutir um tema encarnado, que se torne percepção e vida, nesta escrita o intento é pensar-me como professora em processo de formação ininterrupto tenso e intenso, atravessado por dilemas e questionamentos.

Ensinar, pesquisar, investigar e aprender são práticas de vida que criam relevos e movimentam as estruturas educacionais e sociais. Se aposta na instabilidade do que é compreendido e percebido como sólido, estático, fixo e anestesiado. Estar em estado de anestesia é uma condição cotidiana para suportar os problemas, dilemas, imposições governamentais, normas e regimentos, há um reino da anestesia do qual raramente se submerge para viver um relâmpago passageiro de uma experiência estética que compõe um viver estésico, uma ruptura efêmera neste cotidiano adormecido pela indiferença.

Compreende-se que ensinar exige provocar tensões, configurar um novo hoje e provocar um amanhã inusitado, transformar pessoas, promover pensamentos, construir um mundo novo envolto pelo comprometimento e a participação, em especial, quando se fala e articula ações no ensino de Artes, que rompe com a barreira do saber cognitivo, das habilidades técnicas, do processo de codificação e decodificação ou reprodução de processos. Muito mais do que desenvolver habilidades o ensino de Artes aposta em valores éticos, estéticos, aptos a tornar-se potência à existência do ser em sua humanidade, liberando-o das amarras autoimpostas de um modelo único de aprender, criar e viver a arte enquanto espaço educacional no ensino superior.

Os valores estéticos carregam uma força capaz de gerar desestruturações as quais provocam a existência de experiências, aí reside o poder das artes em libertar o ser humano de seu estado naturalizado de anestesia e lhe permite encontrar novos rumos para seu 
aprender composto por suspiros de estesia. Um desfrutar de novos rumos, encontros, circunstâncias a serem vividas que desabrocham com o sentido do sentir.

O artigo que se desdobra apresenta uma dupla provocação: tensões aquilo que tenciona, que gera uma fricção e intenções ações com objetivos, interesses, ousadias e porque não desejos?

Tem como objetivo provocar, através da língua escrita, rasgos de experiência vivida e formada pela sensação da estesia em uma turma de estudantes de Artes Visuais do Ensino Superior, curso de licenciatura e bacharelado (turma mista) em uma universidade federal do Rio Grande do Sul.

A provocação foi criar um objeto gráfico-visual a partir do estudo do conceito de estesia em Picosque e Martins (2012) de forma a tornar compreensível este conceito e vivenciar um momento de experiência, como algo que nos passa e nos transforma, a partir dos estudos de Jorge Larrosa (2002), articula temas como corpo, sensação, estesia contrapondo-se a anestesia do mundo contemporâneo e experiência, relacionando-os com as produções gráfico-digitais através de uma a/r/tografia (pesquisa baseada no ensino de artes), que visa pensar o professor como uma tríade: professor, pesquisador, artista, ao perceber seu trabalho enquanto ação e interação formativa e contextual.

O método de análise inclui a postura fenomenológica, o mesmo articula com verdades provisórias em contínuo processo de transformação, há um entrelaçamento entre o sujeito que investiga e o objeto investigado, a linguagem mostra-se como mediadora para escrever acerca da realidade provisória. Refere-se a uma abordagem processual, descritiva e considera os fatos que estão além das aparências, os registros ocorrem por imagens (textos visuais).

Os objetos gráfico-visuais produzidos foram substrato para a compreensão da estesia, enquanto prática artística, que ecoa na aprendizagem dos estudantes sendo, um meio e não o fim de uma experiência vivencial.

\section{Da imperfeição: tensões}

O que é arte? O que pode a arte? Por que isto é arte? O que é estética? Como ocorre uma experiência estética e estésica? Dúvidas que perpassaram séculos e permeiam o imaginário de múltiplos estudiosos, não são questões de simples resolução, visto que, não existe uma resposta única e universal, as possíveis ponderações são sempre provisórias, efêmeras e, porque não dizer, contraditórias. 
possa ser, é a visão da arte como manifestação da beleza, e da beleza como aquilo que agrada (sem suscitar desejo). (TOLSTÓI, 2016, p. 51).

Pode-se dizer que a arte configura uma composição de rasgos, fragmentos, pedaços contraditórios e imperfeitos, um plano de questionamentos e relações calmas e turbulentas, lentas e apressadas, flexíveis e estáticas, inquietas. Um espaço de experimentações, proposições, invenções, transfiguração e diluição dos espaços, onde não há uma precisão matemática e certeza geométrica, cujos valores de simetria, harmonia, unidade na diversidade, figura fundo, linearidade e plano cartesiano não são os elementos primordiais e constitutivos do fazer arte, e sim, alguns instrumentos que compõem o plano de criação.

A experiência transformada coloca a vida em jogo, possibilita sair do estágio de anestesia e pôr a alma-corpo a bailar e enlamear-se pelos acontecimentos que colocam o sensível em evidência. Serres (2001) em sua poética/corpo contribui ao ato de pensar sobre o nascimento, o momento mágico que nubla a barreira entre o não sentir para o sentir, da indiferença para o amor feito presença.

"Meu corpo negligencia um grupo de formas e adota outro. Distingue-se dos demais seres vivos por suas metamorfoses" (SERRES, 2004, p. 51). Ele é, afinal, nossa existência materializada e estetizada, à medida que meu corpo transforma-se envolto por uma neblina virtual, política e ambiental, uma vida inteira ao redor dele se move, a vida se desloca, modifica-se, se estrutura por lutas, ganhos e perdas, ordens e desordens.

Para Serres (2004) nosso corpo movimenta-se, transforma-se, não de forma linear e planificada, menos ainda para defender um funcionamento termodinâmico do organismo contra o processo de degeneração. As transformações escolhidas pelos seres humanos podem ser caminhos inesperados, que a genética não poderia prever. Tornar-se um excelente pianista requer estudo contínuo, dedicação diária e treino; compor-se como um filósofo requer questionamento, leituras, exegese; configurar-se num exímio escultor não basta ter a madeira como matéria a ser moldada, ela precisa tornar-se parte de seu corpo, de sua composição; por estes fatores que se fala em "metamorfoses corporais", ao negligenciar um grupo de formas e ater-se a outros o corpo varia, apreende espaços, desenvolve saberes.

Landowski (2005) instiga o pensamento ao referir-se ao conceito de acidente, a possibilidade inesperada de ocorrer uma experiência de estesia, no momento em que viver ou sobreviver estabelece uma relação com os sentidos. Acontece um milagre destinado a suprir o tempo de espera, preencher o vazio, provocar êxtase, ir para além da banalidade das aparências do cotidiano, criar um mundo carregado de sentido. É o momento estésico, uma ruptura com a existência que lhe sucedeu, uma fratura na ordem das coias, um fluxo, uma 
descontinuidade imprevisível, efêmera, uma luta contra a banalidade automatizada de todos os dias.

A acadêmica, em sua aridez feita de normas, regras, modelos e conceitos, demove a oportunidade de respirar. Interessa neste clima árido e seco criar fissuras para o ar passar pelas narinas, adentrar os pulmões e se dissolver pelo corpo através da corrente sanguínea. Há uma exígua camada de ar junto ao rés do chão e desta retiramos o oxigênio necessário há nossa sobrevivência.

Enquanto estudante e professora, nós estamos acostumados a viver com o ar rarefeito que permite apenas a anestesia, a reprodução de normas, técnicas, modelos, procedimentos pedagógicos, inebriados por um processo de construção/continuação de um dado modelo executável. Com este ar rarefeito é difícil levantar, há tontura, um estado de apneia na tentativa de soltar os ferrolhos enferrujados das janelas do aprender para deixar o ar que envolve processos de criação adentrar os pulmões, oportunizando o inventar, inverter a lógica linear, provocar sensações, sentir e fazer-se sentir.

Provocar tensões, proteger nossa existência, tornando o corpo potência para o ato do aprender, imerso em imperfeições, tensões, medos, angústias, desafios, espaço que faz emergir gotículas de oxigênio para a vivência estésica.

[...]. Na experiência estésica - esse momento em que, como escreve Michel Tournier, as coisas se revelam na sua "essência", "sem buscar outra justificação que a sua própria perfeição" -, pode ocorrer que a realidade faça sentido de um modo quase fusional, como se o contato com o "perfume" dos objetos bastasse para tornar o sujeito plenamente presente ao mundo - e o mundo imediatamente significante. (LANDOWSKI, 2005, p. 94).

Revelar-se em sua essência, abrir brechas para o aprender feito com sentido em um ato de fusão, que transforma ações banais em acontecimentos inusitados. $\mathrm{O}$ ensinar está envolto por uma nebulosa de acontecimentos que podem provocar aprendizagens sensíveis e inesperadas. Da imperfeição e incerteza presente na leitura de um texto como pretexto ao debate e compreensão conceitual, podem emergir desejos, curiosidades, criações gráficas embebidas em sensações. Um texto é um mundo de expectativas, leituras, flexibilidades, conceitos, assim como a tela se apresenta ao pintor, uma história a ser contada.

Os olhos tocam as letras que forma palavras, compõe frases e criam conceitos. Ler o mundo através das palavras, provocar o sensível inebriado pelo anestésico, romper o modelo único do monólogo narrado, eis o desafio de ser professora-artista-pesquisadora: criar abalos nas certezas a ponto de gerar aprendizagens. 
Fluxos sanguíneos Desejos libidinosos Sensações incompreensíveis e difíceis de serem aprisionadas em palavras

Silêncios Sons Instabilidades Tensões e crescimentos, impossibilidades de gritar, vibrar

imaginar outros espaços... Sentir, viver encontros... Suspender as amarras que nos amordaçam, romper com a organização orgânica. Viver, ser, existir em movimentos e fluxos...

Brincar com a imaginação, Caminhar sobre caminhos não percorridos, Andar por corredores mal iluminados e dançar ao ritmo dos batimentos cardíacos.

Mudar, transformar, tornar carne o aprender... Deleitar-se com os saberes, sentir asco e indiferença, desejos e interesses, movimentos...

(JH, junho 2015)

Aprender a partir do rastro como potência de transformação, é uma das formas de reconstrução do processo educacional, desestruturação das estruturas curriculares com a intenção de permitir o florescimento da sensação do "acontecimento" que se dá pelo encontro (a força que reage no entremeio das relações que se estabelecem), pelo sensível que perpassa o corpo como uma onda vibrátil, modificando continuamente quem se é.

Colocar-se em alerta, inquietar este corpo que não aguenta mais andar de bicicleta, andar a pé, sentar, deitar, demover a anestesia e permitir que as relações comecem a fazer sentido, através do fruir, desafiar-se e viver encontros com outros corpos. "O corpo é porta primária de todo o conhecimento e por isso o entendimento corpóreo se faz fonte para o conhecimento" (PICOSQUE, MARTINS, 2012, p. 35).

O corpo abre-se a experiência sensível, uma possível vivência estética que altera as sensações carnais e mentais, "estética como estesia, uma capacidade que permite a percepção, através dos sentidos, do mundo exterior" (PICOSQUE, MARTINS, 2012, p. 35). O corpo se metamorfoseia nos espaços que ocupa, nunca está pronto, à medida que se transforma interfere no ambiente.

Os olhos produzem imagens pelo movimento do olhar, abrir e fechar as pálpebras, fixar imagens e num relance mudar o foco, ver com o tato e o olfato, não enxergar, mas 
perceber, com todos os sentidos corpóreos, colocando o corpo em suspensão, em vibração, em produção plástica. O corpo pode esvaziar-se de si, para produzir outros corpos em si, um corpo gravura que se movimenta pela cidade e vira pó, um corpo silêncio que se gruda aos espaços de paragem e grita através das palavras não ditas, corpo feito de carne e arte que se funde com o texto que aprecia no ato leitor.

\section{Intenções/rasgos: processos de criação}

As intenções se fazem sentir e existir, nos mais inusitados encontros. Das letras impressas ao toque ocasionado pela pele que entra em contato com a fria epiderme da celulose do eucalipto feito pasta e ressecada, possibilitando a criação do papel que abarca as letras que são decifradas pelo corpo e o ato de olhar. Da pasta que se transforma em finas camadas até o corpo que emerge de seu cotidiano anestésico, há a potência da estesia ocorrer no mais sutil dos encontros possíveis.

Desafia-se a viver arte e educação como potência para contestar, fazer parte, intervir, interagir, penetrar no fluxo das relações sociais, compreender-se como uma engrenagem vital do processo de aprendizagem, um ser que se movimenta e é movimentando, atravessado pelo cotidiano que rompe com sua pele, penetra em sua musculatura e faz vibrar seu sistema nervoso, ao tornar-se corpo-arte-cidade-academia-aprendizagem, não mais um mero observador, mas um interventor, crítico, propositivo e criador.

Neste emaranhado educacional a estesia é uma condição de sentir as qualidades sensíveis do que existe, e possibilita sua captura através dos sentidos, de forma a ser vivida, experimentada, processada. No Ensino Superior, a cada novo encontro, percebe-se uma elevada valorização da técnica, da objetividade, do modelo padrão, da certeza estilhaçando o espaço da criação, da dúvida, do medo e inseguranças, não há abertura ao irreverente, questionável e novo.

O campo acadêmico inscrito num caráter democrático, cuja pretensão é mostrar-se como um "tempo-feito-livre" (MASSCHELEIN; SIMONS, 2015), vive aprisionado na insurgência dos discursos que demarcam sua estrutura como um mecanismo de reprodução e fomento das desigualdades sociais, encontra-se a serviço do capital numa lógica social em que o conhecimento é um bem econômico. O que o torna perverso é a incapacidade de perceber os jogos de poder em constante tensão e a visão distorcida que a faz crer em sua liberdade, autonomia e poder pedagógico, alicerçado numa ótica neutra e apolítica.

O mundo acadêmico, em diversas situações, estilhaça o espaço do sensível e deturpa a existência da sensação (na maioria dos encontros designados ao aprender). Neste recorte 
temporal se pretende narrar de forma poética/vivencial a existência como professorapesquisadora de um momento que compõe uma ruptura da solidez conceitual transformada em criação artístico-gráfica.

Era manhã, como qualquer outra sem nada de especial, o vento soprava incansavelmente e as janelas precisavam permanecer fechadas a fim de evitar seu fechamento inesperado, havia certa de trinta acadêmicos do curso de licenciatura e bacharelado em artes visuais, mais uma aula de quatro períodos do componente curricular de História Teoria e Crítica da Arte Contemporânea. Há tempos nossas conversas conceituais colocavam o corpo em evidencia, como pressuposto da nossa existência, muitos momentos o eu-corpo se fazia presente, mas não havíamos tido a oportunidade de tornar este corpo vibração, sensação e estesia.

Estranho termo, desconhecido por muitos, lido e relido nos escritos de Picosque e Martins (2012) em minhas noites insones; meu desejo era compartilhar um conceito e talvez torná-lo vida, experiência, processos de criação. Toda sensação implica uma diferença de nível, uma aprendizagem e um desafio, o texto escolhido para o debate era mais uma oportunidade de pensar a arte em sua multiplicidade.

Um texto não é apenas uma escrita, é um mundo, uma condição de processamento estético, um constituinte do universo da linguagem, um possível encontro com o corpo que sente e opera de forma imprevisível tornando-se estésico. Quanto maior a relação estética do humano com os desafios do mundo seja a leitura, o debate, a ação impressiva e a ação do corpo que opera o aprender sem automatismo, maior é a possibilidade de se abrir brechas a estesia.

Tornando-o gatilho à experiência a leitura textual compôs-se por uma estratégia ao aprender, neste plano de expressão o corpo capta, sente as pulsões, vive as intenções e produz uma experiência que é sentida, tornando-se sensação. Deleuze (2007) instiga o pensar e questiona a possibilidade de existir sensações que ocorrem na carne e compõe o corpo.

\footnotetext{
A sensação tem um lado voltado para o sujeito [...] e um lado voltado para o objeto [...]. Ou melhor, ela não possui lados; ela é as duas coisas indissoluvelmente, é serno-mundo, como dizem os fenomenológicos: ao mesmo tempo eu me torno na sensação e alguma coisa acontece pela sensação, um pelo outro, um no outro. Em última análise, é o mesmo corpo que dá e recebe a sensação, que é tanto objeto quanto sujeito. (DELEUZE, 2007, p. 42).
}

Martins e Picosque (2012) compõem pontes de pensamento num emaranhado de dicotomias entre um corpo que se deixa capturar pelo sistema e torna-se máquina de produção/reprodução; aquele que foge ao encontro e anula a experiência e, em contrapartida o 
corpo que permite sentir e viver uma experiência estética em plena intensidade. Seus escritos fazem emergir questionamentos, os quais provocam sufocamento: "Como provocar de um modo singular o mergulho na experiência e ser atravessado e movido por ela?" (MARTINS; PICOSQUE, 2012, p. 115).

O corpo que se torna objeto e sujeito ao mesmo tempo está aberto à experiência estésica. O sujeito estésico apreende as impressões impressivas, elabora um fazer feito de afetações sensoriais, compõe-se como possível ser de cognição/aprendizagem, reconhece os sentidos e se faz conhecer. O sentir e o fazer são correlatos da compreensão, o ser volta-se a si, aprecia, avalia, pondera e reconhece as impressões e expressões que o afeta. A estesia é um sentido que se faz sentir, altera o olhar do ser acerca do mundo, das produções, da linguagem e da cultura.

\section{Emergir da anestesia: experiência no ensino superior}

A prática pedagógica realizada em uma turma do ensino superior, que envolveu de forma sutil uma experiência estética envolta pela sensação estésica, solicita espaço para adentrar esta escrita e deixar sua marca, uma pluralidade, ao criar narrativas gráficas enviesadas pela mão dos acadêmicos. Movimenta-se por artefatos que assumem o papel de dispositivos à criação; configura aberturas sensíveis que colocam o corpo em estado de estesia; imerso num espaço educacional cujo "tempo-feito-livre" (MASSCHEIN; SIMONS, 2015) possibilita a democratização do aprender.

Interessa as multiplicidades de forma que a arte dentro do espaço educacional conquista quando rompe com o modelo tecnicista e cria práticas propositivas, por mais efêmera que pareça a ação surgiu de uma inquietação: Como viver a estesia quando se vive inerte na academia?

A estesia é como uma poética da dimensão sensível do corpo que suscita em absoluta singularidade uma experiência sensível com objetos, lugares, condições de existência, seres, comportamentos, ideias, pensamentos, conceitos. (MARTINS; PICOSQUE, 2012, p. 35).

Atravessado por este corpo plural formado por singularidades, repleto de vontade e potência estésico e não anestésico (MARTINS; PICOSQUE, 2012), cuja dualidade corpo e mente, massa e espírito, consciência e carnalidade tornam-se inexistentes, o que resta é um emaranhado de relações pulsátil, complexa, frágil e singular.

A arte, a estética e a beleza, são termos conceituas que abarcam inúmeras definiçõos, em alguns casos complementares, em outros contraditórios. Para fins de compreensão, será feito um recorte atravessado pelo conceito de estética em Rosenfield (2006), têm-se 
consciência de que esta é uma escolha conceitual dentre uma multiplicidade de filósofos estetas.

A palavra "estética" vem do grego aísthesis, que significa sensação, sentimento... a estética analisa o complexo das sensações e dos sentimentos, investiga sua interação nas atividades físicas e mentais do homem, debruçando-se sobre as produções (artísticas ou não) da sensibilidade, com o fim de determinar suas relações com o conhecimento, a razão e a ética. (ROSENFIELD, 2006, p. 07).

Na concepção de Rosenfield (2006), a origem do termo está diretamente relacionada com a carne, o corpo que pulsa, vibra e se sente apto a viver sensações que abalam sua estrutura biológica e mental. Para fins didáticos, há uma separação entre mente e corpo, entretanto compreende-se que o ser humano é uma unicidade e as afetações estéticas colocam em funcionamento este corpo uno, no qual as experiências causam oscilações físicas e fomentam pensamentos, questionamentos e inquietações.

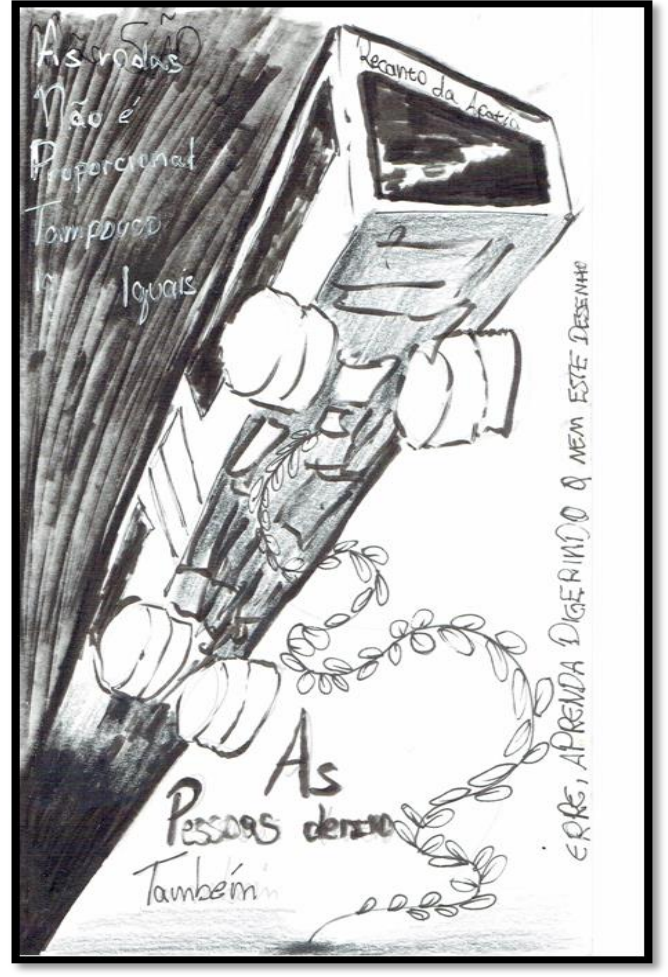

Figura 1: Estudante A - objeto gráfico-visual Fonte: autora

A proposição estésica (que ora se desdobra) estava relacionada à potência que emana de uma leitura textual, cujo intento era perceber os múltiplos nuances sensíveis a partir do verbo tornado vida e os efeitos que produz na epiderme dos estudantes. O texto lido foi escrito por Mirian Celeste Martins e Gisa Picosque (2012): "Revelações do corpo: estesia, conhecimento". A figura 1 oferece a composição de um veículo com rodas de tamanhos diferenciados a fim de demonstrar que a suavidade do objeto circulatório em contato com o solo só ocorre quando não há imperfeições, mas sim, uma sincronia, um mesmo ritmo. Mas a vida é feita de imperfeições como as dobras da pele, cada sulco retrata um encontro, uma experiência, possíveis aprendizagens. Serres (2001) nos convida a pensar no sentido da dobra que a pele faz sobre si mesma o que mostra que ainda estamos vivos.

Sem dobra, sem contato de si sobre si mesmo, não haveria verdadeiramente sentido íntimo, nem corpo próprio, muito menos cenestesia, tampouco verdadeiramente esquema corporal; viveríamos sem consciência; apagados, prestes a desaparecer. (SERRES, 2001, p. 16). 
De forma análoga a citação de Serres (2001) há nas figuras 2 e 3 uma severa crítica ao mundo globalizado, capitalista, sob uma falsa ideia de inclusão e respeito à diversidade, alicerçada na ótica da exclusão que remove de forma sutil a potência de vida na contemporaneidade. Evidencia-se um andar desregrado, composto pela cegueira social, o reflexo da anestesia.

A experiência estésica não é apenas uma negação da anestesia, todavia como Landowski (2005) esclarece o momento específico desta experiência é sumariamente acidental, caracterizado por um evento pontual e negativo. Este evento produz uma sequência de significações heterogêneas que se limita a apresentar eventos contrastantes entre a existência do sentido denotativo por um lado e apreensível no êxtase por outro, como forma de revelar uma essência descontínua de determinada existência.

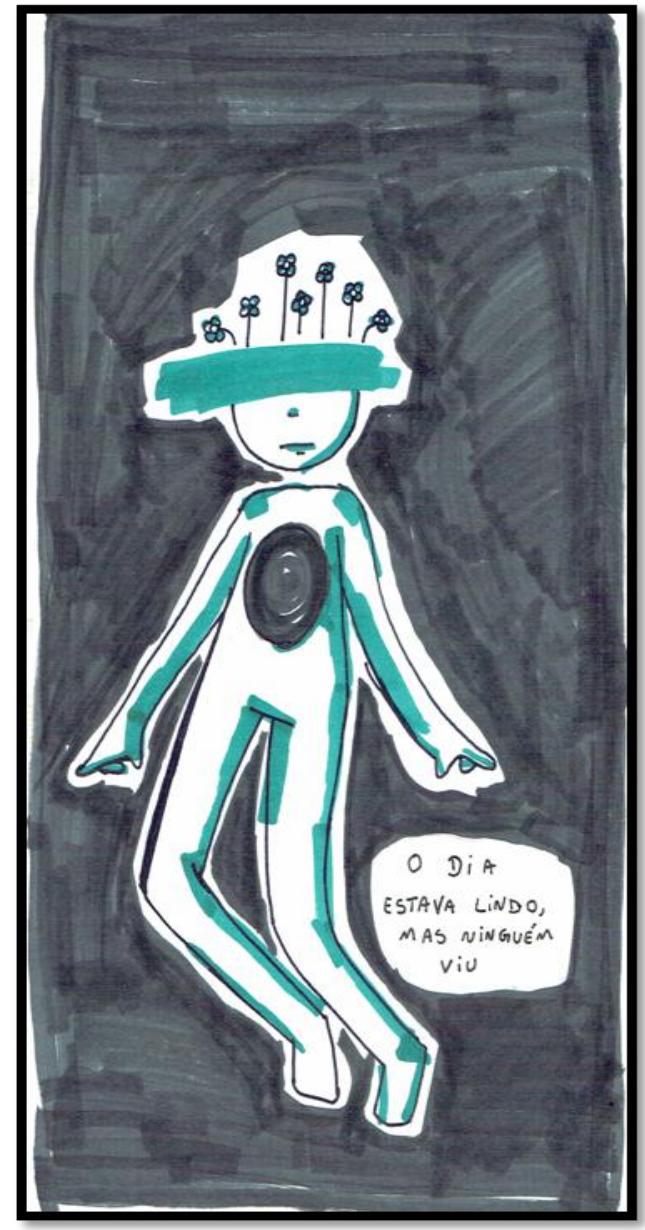

Figura 2: Estudante B - objeto gráfico-visual Fonte: autora

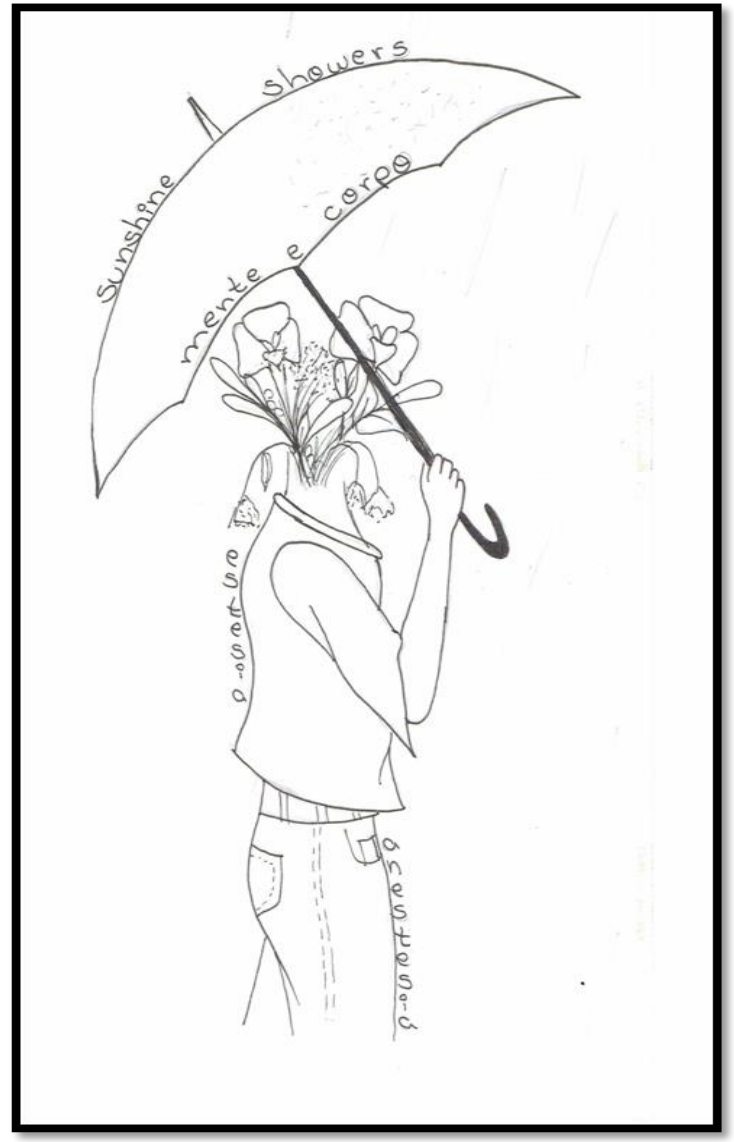

Figura 3: Estudante C - objeto gráfico-visual Fonte: autora

$\mathrm{Em}$

contraposição a Landowski (2005) se aposta na

estesia como um momento de sincronia entre todos os órgãos do sentido de forma a provocar sensações, aptas a remover a venda dos olhos que nos impede de ver a beleza do dia. Não anula nossa face transformando-a em flores, mas dá a ela um brilho no olhar convidando-a a 
viver um momento estético. "Somos preparados biologicamente para sermos sensíveis, para roçar o mundo com nossos órgãos dos sentidos transformando essa coleta sensorial em informação para gerar processos cognitivos” (PICOSQUE; MARTINS; 2012, p. 35).

Há um prazer sensível e inteligível quando ocorre uma experiência estética, causa transformações poéticas e reflexivas, tendo como pano de fundo uma forma de vida humana como arte. O fenômeno estético nasce no corpo e a ele se dirige, há um processo de entrega, sentimento, visceralidade, arte e beleza. "O corpo é porta de entrada de todo conhecimento e por isso o entendimento corpóreo se faz fonte para o conhecimento" (PICOSQUE; MARTINS; 2012, p. 35). Uma experiência estética e estésica só ocorre quando o corpo está aberto às vibrações, sensibilidades e influências tanto internas como externas, num movimento de estar disposto à: sentir os fluídos do ambiente e deixar-se penetrar pelas relações, não endurecer os pensamentos em certezas e modelos pré-fabricados, estar junto, experimentar emoções, sentimentos e paixões, silenciar os pensamentos e acalmar os batimentos cardíacos, confiar no desconhecido.

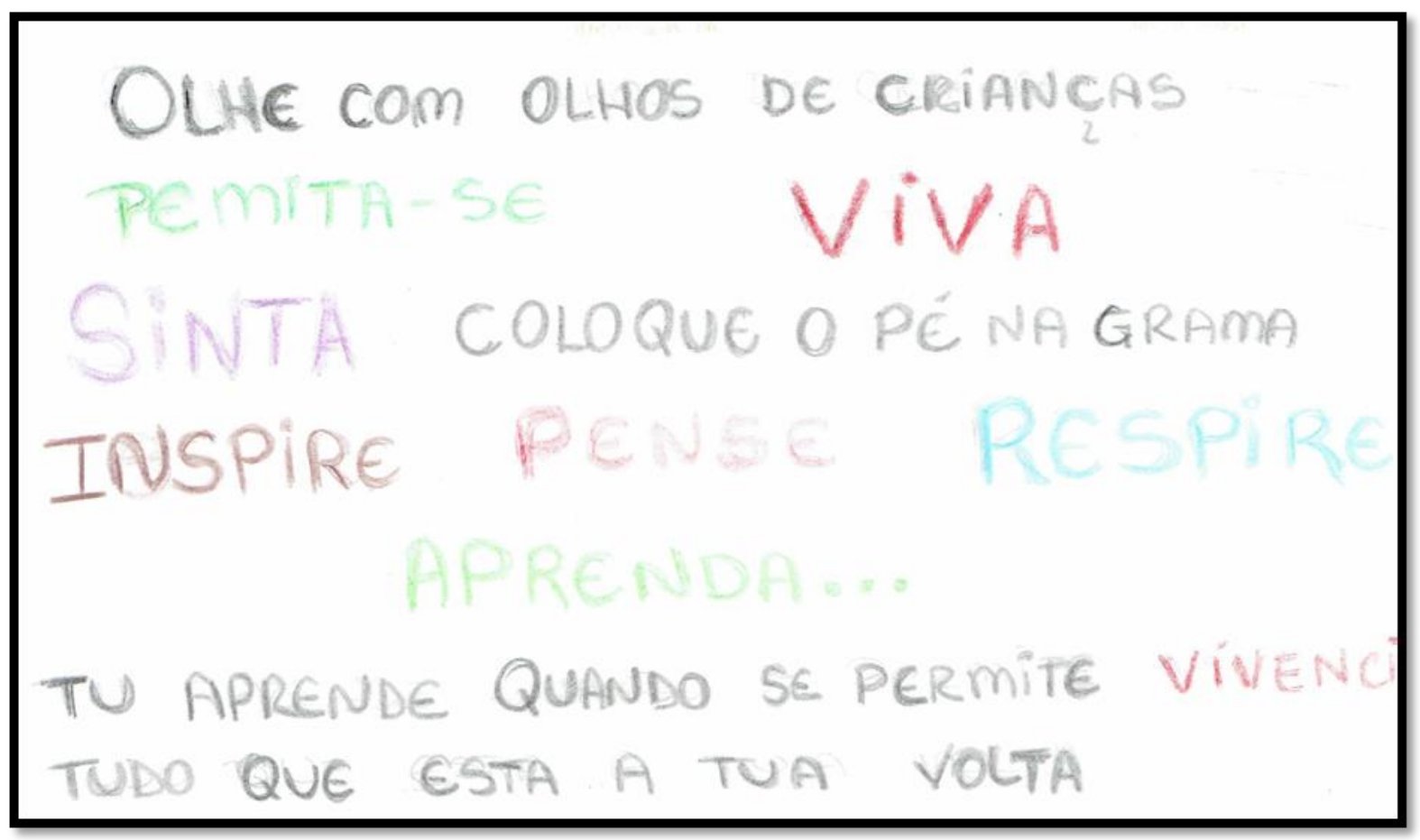

Figura 4: Estudante D - objeto gráfico-visual Fonte: autora

Viver uma experiência estética e estésica requer um processo de reeducação dos cinco sentidos, retirando-os de um procedimento anestésico oportunizado pelas relações de trabalho atuais, os sistemas de interação e convivência social, o isolamento autoimposto decorrente do desenho da cidade contemporânea, a universalização dos aparatos tecnológicos e o sistema de 
conexão via rede sem fío, dentre outros fastos contemporâneos que visam à solidão e o isolamento, ampliando o leque de doenças como síndrome do pânico e depressão. Sistema apresentando na figura 5 .

Interessa notar que ao falar em estesia e debater acerca do corpo e sua potência de criação e transformação, as imagens gráficas que emergem das produções dos acadêmicos estão sumariamente voltada a fatores como isolamento social, depressão, solidão, tristeza, uso de psicoativos como drogas ilícitas e medicamentos controlados. O impacto no psicológico docente destas imagens remete ao adoecimento da psique social e o quão perigoso é provocar tensões que criem rupturas com a anestesia autoimposta destes estudantes, acostumados a dessensibilização que enseja uma crise nos sentidos tornando-os amortecidos.

A anestesia deixa marcas profunda em nosso corpo, em nossas ações, baixa nosso nível de criação tornando-nos meros executores de tarefas, indiferentes, insensíveis, infelizes e doentes, "[...] não baixamos mais os olhos para o lixo jogado no chão, o corpo estendido no chão" (PICOSQUE; MARTINS; 2012, p. 37).

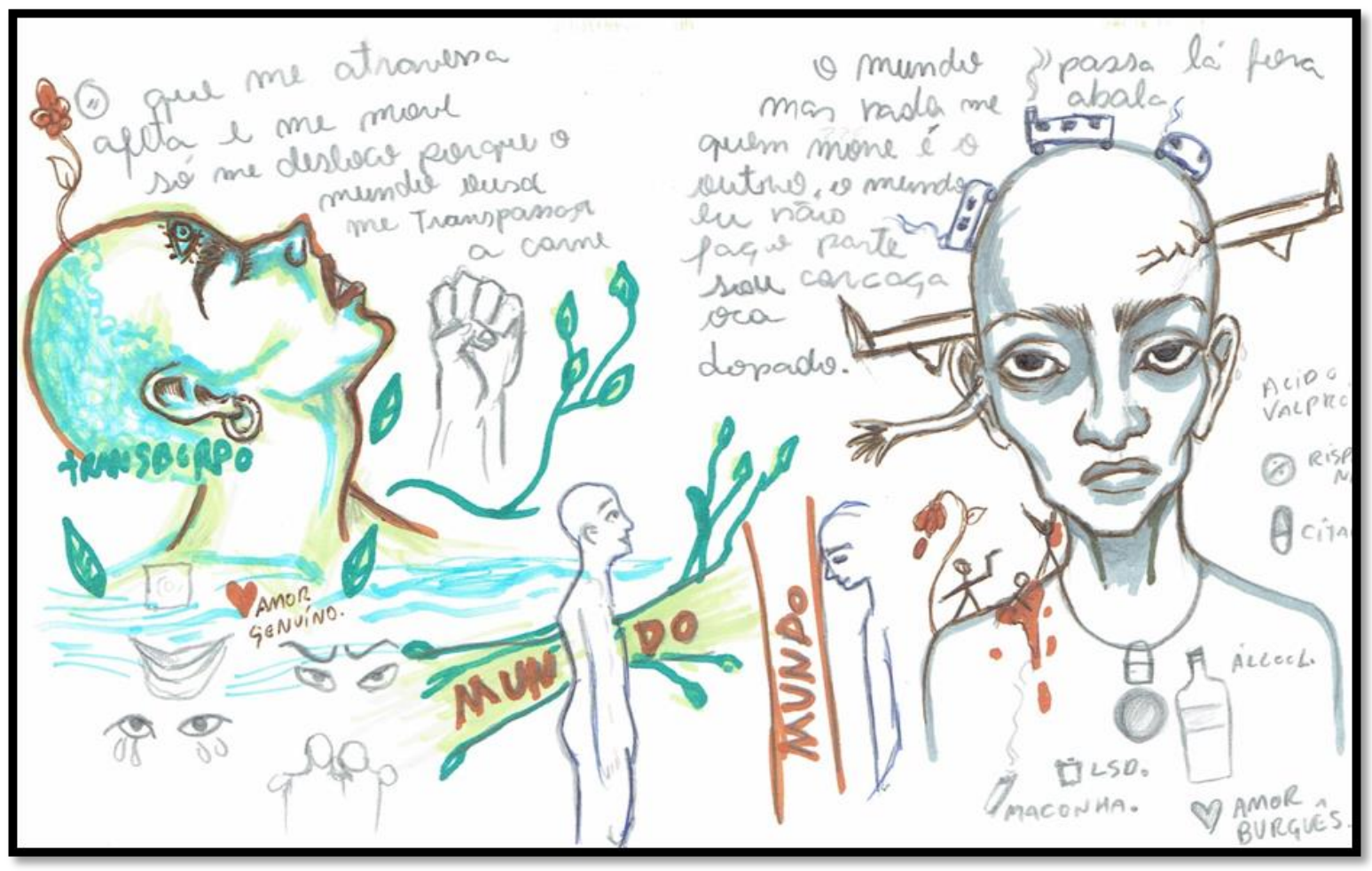

Figura 5: Estudante E - objeto gráfico-visual Fonte: autora

Faz-se jus a um processo de transformação no qual a sagacidade da pele em contato com uma infinidade de espaços e referências mede as experiências, oportuniza encontros sensíveis e tangencia relações mediadas e imediatas atravessada pela sensação. Sensação compreendida com vibração diferente que passa pelo corpo e arrepia os pelos, a musculatura 
fica rija, o ar torna-se pesado, há um arrebatamento, uma experiência sensível e intensa. Uma visão do mundo que obriga a um dês(co)lamento. Um instante, uma força transbordante de sentidos, delírio, pensamentos turvos e confusos. Abrem-se derivas para uma escrita em vácuo, em fluxos. Produz formas, organiza tempos, cria medos e coragens; possibilita, impossibilita, instiga, inventa mundos possíveis, impossíveis, ampara encontros e desencontros, não deixa a vida se asfixiar, mas, causa pequenas sufocações. Não pode ser medida, nem representada. Varia conforme sua ordem tátil, visual, gustativa, olfativa, psicológica, não produz significados cria sentidos.

É sempre novo, um novo encontro, outras percepções possíveis. Compõe-se por forças opostas que se tramam, exterior e interior, uma ação provisória, um entrelaçamento entre ritmos, ver, ouvir, tocar, cheirar, vibrar, estremecer, emudecer, chorar, amar.

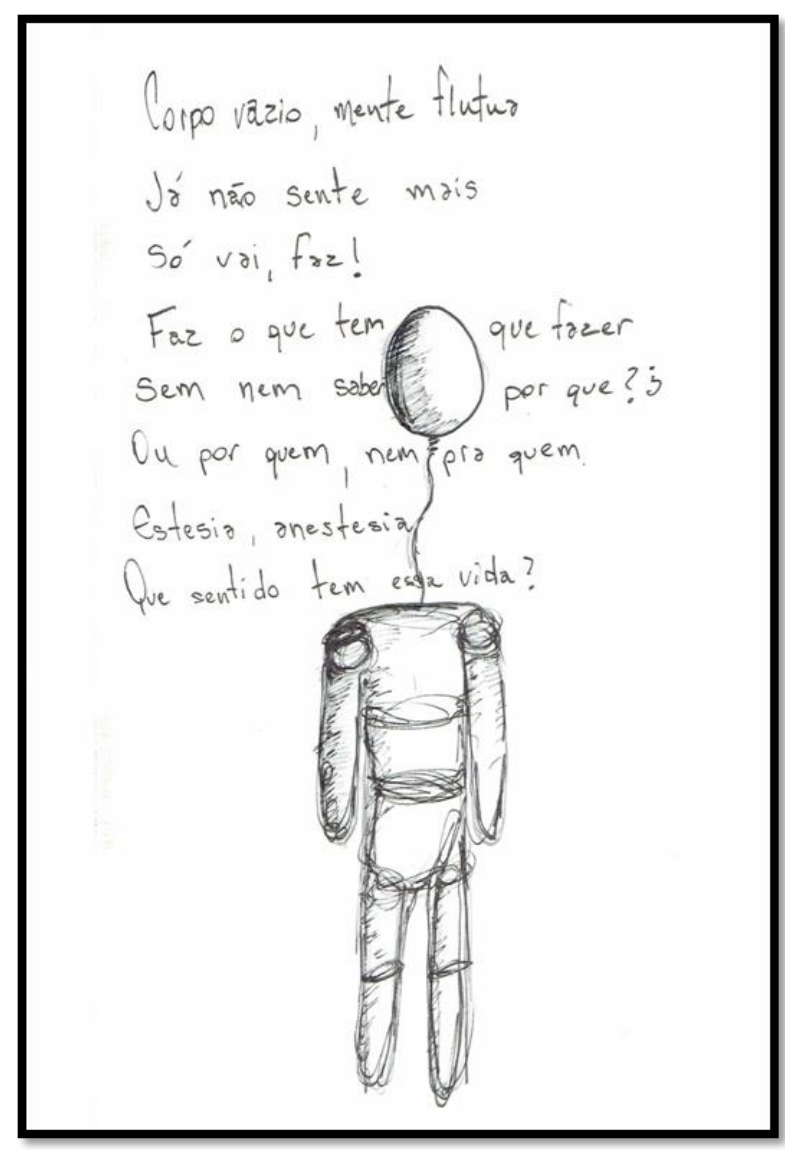

Figura 6: Estudante F - Objeto gráfico-visual Fonte: autora

Vive-se imerso num fluxo contínuo de estimulações estéticas, as quais, em decorrência da agitação contemporânea não nos afeta e atravessa nosso corpo como uma neblina densa que deixa apenas uma umidade em nossa pele, quase imperceptível. Turbilhão de informações, excesso de trabalho, preocupações díspares, informações em escala fenomenal, 
tráfego intenso de automóveis, buzinas, freadas, semáforos com suas luzes intermitentes, batimentos cardíacos acelerados, intensidades efêmeras que não promovem encontros sensíveis e experiências, configuram apenas um cansaço físico e mental.

Existência humana articulada na figura 7, quando o estudante destaca a percepção de uma vida imersa na sonolência de um mundo que coloca o corpo em transe, só é possível viver quando se estabelece uma realidade paralela composta pelo ato de sonhar, quando se sonha é possível suportar as obrigações, as relações, a vida.

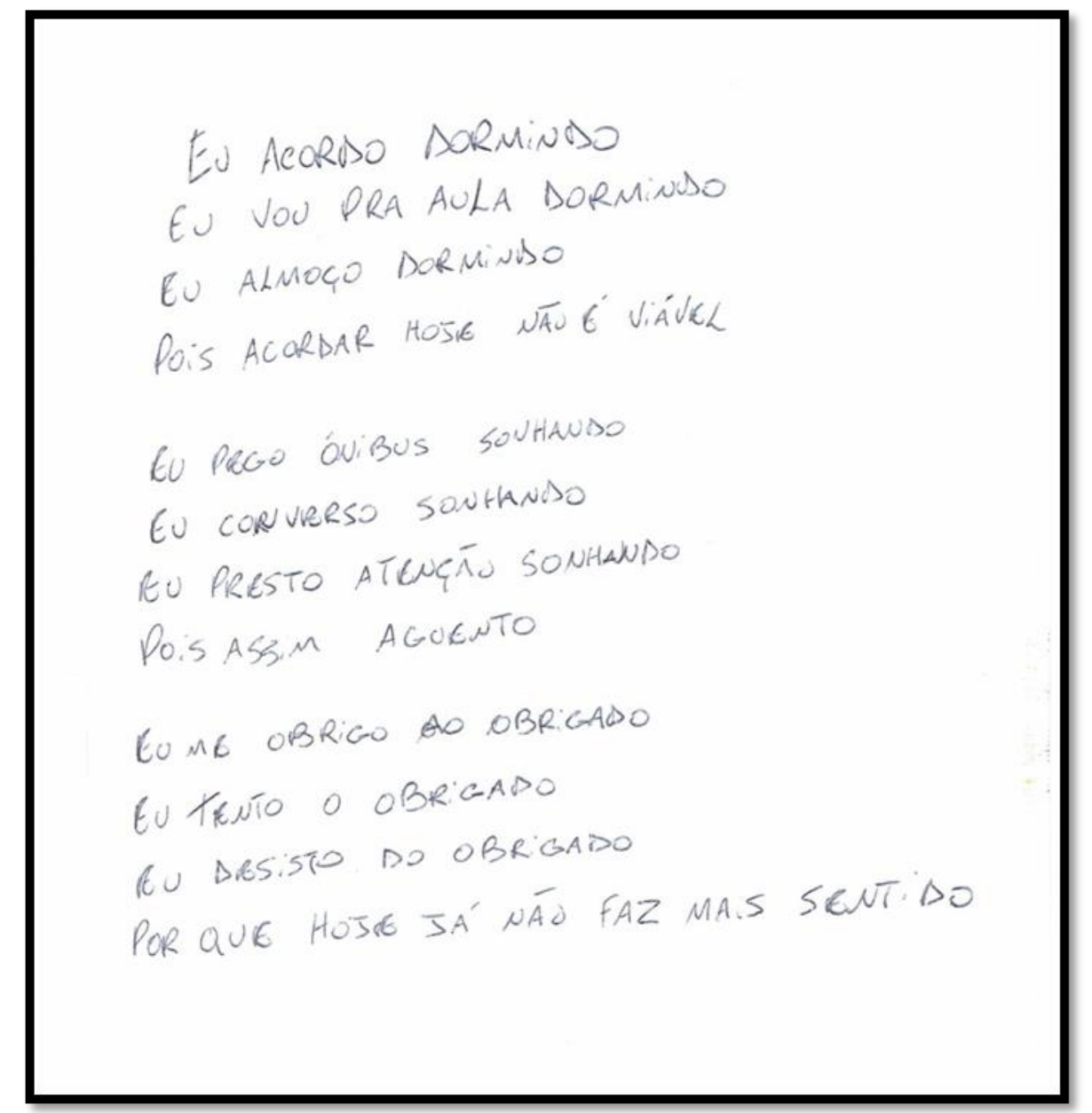

Figura 7: Estudante G - objeto gráfico-visual Fonte: autora

A arte torna a vida suportável. A arte não é entendida como paradigmática, como um mero recurso da comunicação e informação, ou uma forma de linguagem, mas como um veículo de transformação, um potencial de deslocamento, gestação de perceptos (DELEUZE; GUATTARI, 2010), deformação, duplicidade, devires, habitados por forças de transmutação, torrentes cromáticas, rupturas, fissuras, ranhuras, cheiros, gestos, singularidades. Desafios, questionamentos, materialidades e sentidos. Uma cortina fechada, um pedido de silêncio, um 
deslocamento, do espectador para dentro da obra, encontros, sensações e vibrações, caminhos que promovem o aprender.

Viver um ato estético é duvidar do que está dado, do explícito, do modelo, da norma e do padrão. É promover o encontro com o outro, fomentar a relação em sua complexidade, importa perder tempo para aprender, deixar-se sensível as metamorfoses que escapam ao controle da ordem lógica, do significado e do valor. Na estética há uma simultaneidade entre o visível e o sensível como potência do ato de criação, as relações ocorrem de forma concomitante e simultânea no plano de imanência, ou seja, o tempo presente, oportunizando abertura a estesia.

Viver a experiência apregoada por Larrosa aquela que compõe nossa carne, nossa vibração, nossa existência e nos transforma, muda formas de agir e interagir, rompe com modelos e provoca pensamentos.

\begin{abstract}
A experiência, a possibilidade de que algo nos aconteça ou nos toque, requer um gesto de interrupção, um gesto que é quase impossível nos tempos que correm: requer parar para pensar, parar para olhar, parar para escutar, pensar mais devagar, olhar mais devagar; parar para sentir, sentir mais devagar, demorar-se nos detalhes, suspender a opinião, suspender o juízo, suspender a vontade, suspender o automatismo da ação, cultivar a atenção e a delicadeza, abrir os olhos e os ouvidos, falar sobre o que nos acontece, aprender a lentidão, escutar os outros, cultivar a arte do encontro, calar muito, ter paciência e dar-se tempo e espaço. (LARROSA, 2002, p. 24-25).
\end{abstract}

A experiência é alheia a mim, mas acontece em meu corpo. Não pode ser minha, não pode ser controlada, prevista, descrita. Ela é movimento de ida e volta, de relação. Larrosa (2011) destaca que experiência acontece em minhas palavras, em minhas ideias, em minhas representações, em meus sentimentos, projetos, intenções, saber, poder, em minha vontade, ou seja, se dá em meu corpo que se abre ao inusitado, ao estranho, que padece de forma única, singular, particular, própria.

Experiência, ter contato, provar, viver um evento, um acontecimento, experimentar. "Ex-iste" dirá Larrosa (2002) da inexistência para a existência, envolver-se sem medos e medidas, aceitar, surpreender-se, espantar-se, colocar-se em movimento, apaixonar-se. A experiência é singular, pode-se dividir num mesmo acontecimento, mas, a forma de ser afetado é própria a cada ser e impossível de ser repetida.

Permitir ao corpo viver momentos de estesia sentir a vibração dos encontros e colocar o corpo em estado de alerta, parar, sentir, descansar, intervir em territórios, locomover-se, reconhecer o efêmero, provisório, tornar-se humano, abusar dos processos de criação, 
reconhecer as próprias limitações e ir além das aparências, deixar-se penetrar visceralmente pelos encontros. Estranhar-se a si, para permitir-se viver experiências.

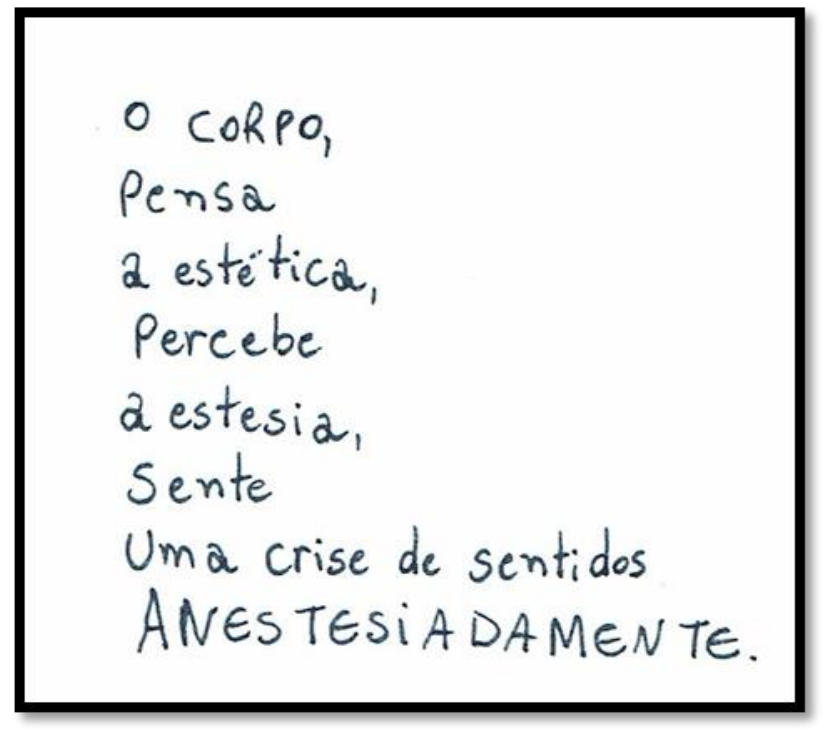

Figura 8: Estudante H - objeto gráfico-visual Fonte: autora

Na esteira poética do estudante $H$, presente na figura 8 é possível criar um laço de

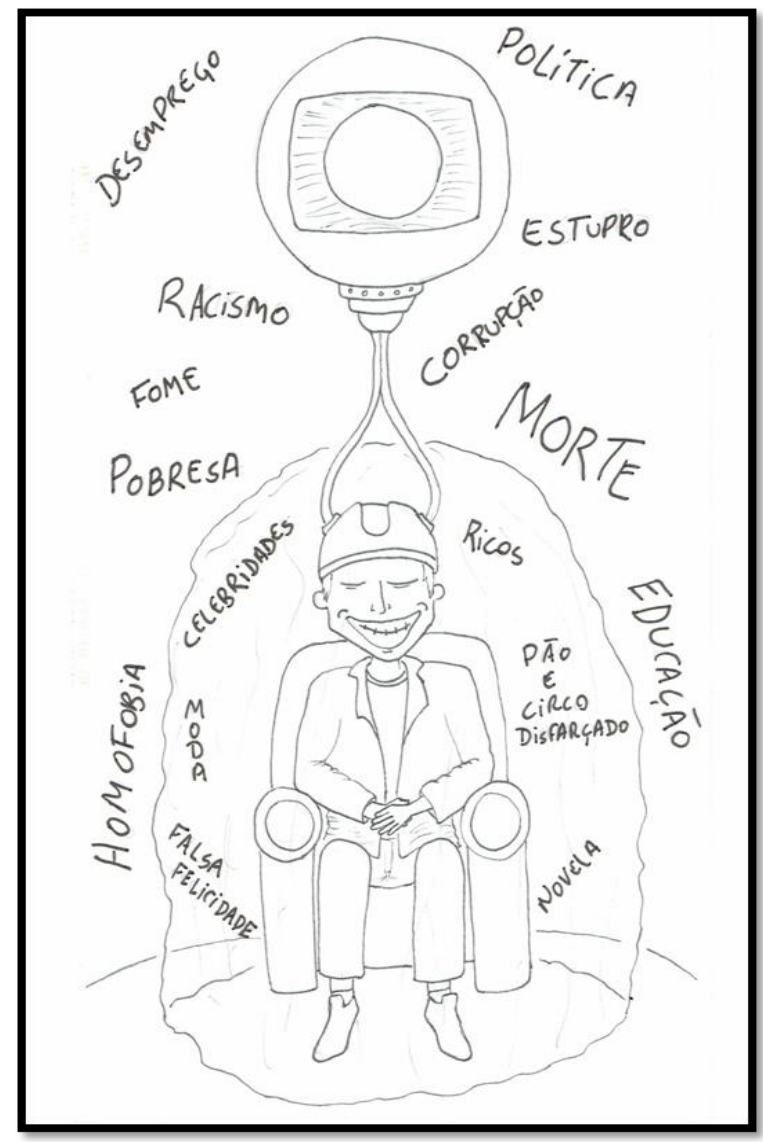

Figura 9: Estudante I - objeto gráfico-visual Fonte: autora afetos que se referem ao corpo, este veículo de projeção e inserção no mundo, invólucro de sentimentos, palavras, aprendizagens, carne, órgãos, vísceras, sangue, neurônios, sensações, condição de possibilidade à experiência, ambiguidades, dilemas e incertezas. Por outro lado às figuras 9 e 10 fazem emergir múltiplos contágios perniciosos há existência.

O corpo inerte da figura 9 mostra esboçado em sua face um sorriso artificial fomentado por uma falsa felicidade, adquirida através da conexão televisiva que produz mundos imagéticos no qual sempre há fortuna, fama, conquistas, diversão e felicidade. O mundo real, fora da telinha, se exprime por entre as rachaduras da casa que está a ruir, dos filhos que estão sendo destruídos pelo uso de ácido e outros entorpecentes, do esfriamento do amor humano e a valorização intensa do egoísmo, individualismo, solidão, adoecimento e isolamento social. 
A figura 10 articula a decapitação dos seres humanos substituindo-os por equipamentos tecnológicos e midiáticos, ação que causa desequilíbrios, dúvidas, questionamentos, inseguranças. Quando o corpo afasta-se do equilíbrio apresenta comportamentos radicais, imprevisíveis, inconstantes, criadores ou reprodutores. A arte joga com o desconhecido, cria palavras, inventa proposições, desenvolve movimentos, convida o não-artista a tornar-se protagonista.

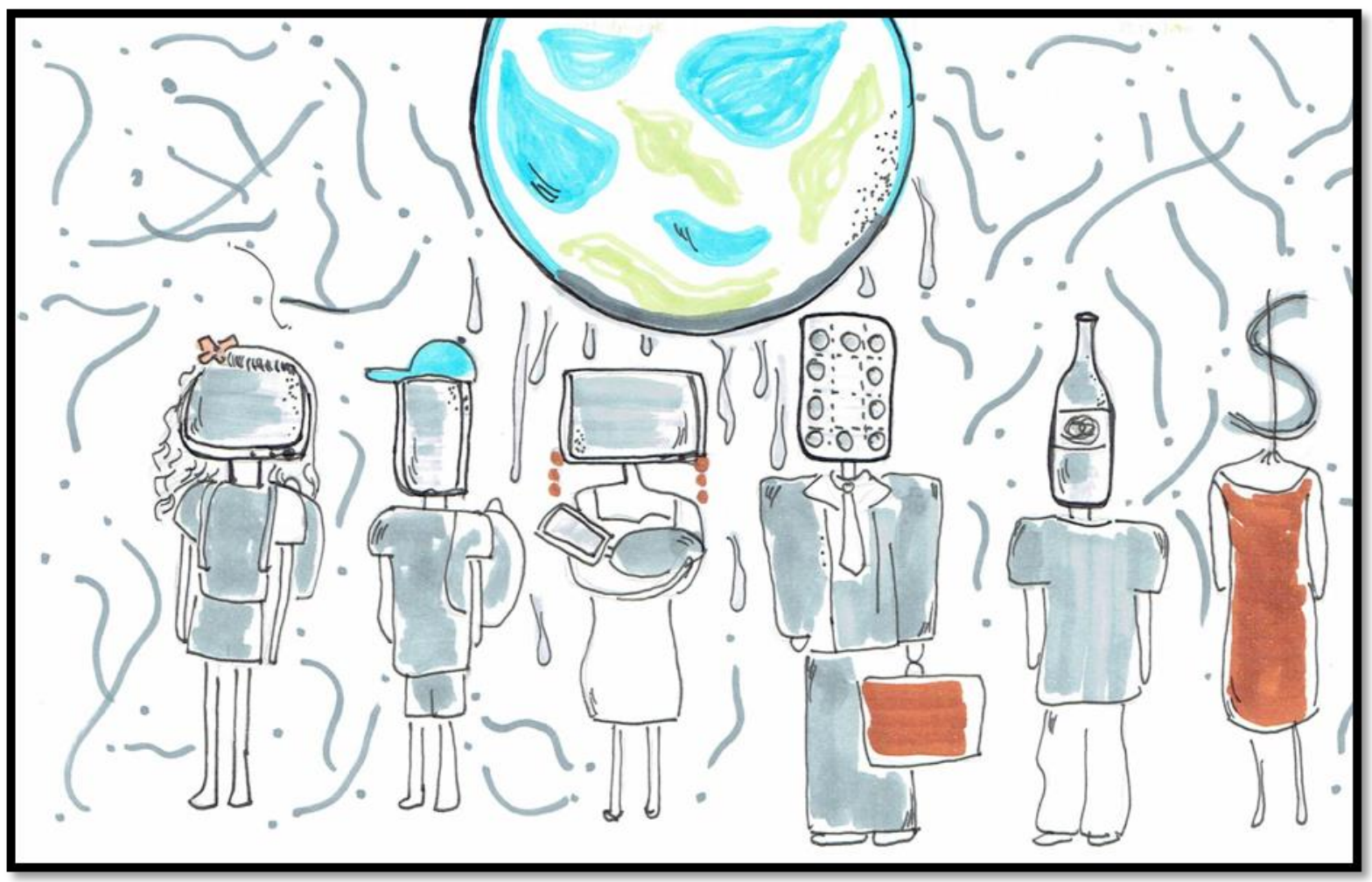

Figura10: Estudante $\mathbf{J}$ - objeto gráfico-visual Fonte: autora

Criar cisões, padrões, medidas, critérios, escalas, normas, sistemas, cortar o caos ao unir o pensar, o fazer e o compreender. Viver à custa das incertezas, do acaso, da improvisação, da simultaneidade dos acontecimentos, fomentar agenciamentos. Deixar margem para o erro e o recomeço, tencionar espaços à dúvida, desconfiança e incredulidade. Há ganhos, há perdas, movimento e engessamento, desafios e medos, coragens!

Deixar-se contaminar de forma estésica é permitir que haja o toque, o desastre, uma ruptura com a representação, o acidente inusitado, quebra com as formas de pensamento único, o experienciar e viver novos ritmos, um deslizamento com sensações, imagens, cores, experimentações, entrelaçamentos com a arte e sua materialidade. Maneiras, meios, fatos, fotos, existências de si, do outro, das singularidades entre corpos. 


\section{Considerações finais}

Uma folha em branco, repleta de marcas, manchas e escritos quase imperceptíveis, um mundo imagético feito de rasgos e inserções clichês. Um papel, um suporte com limites delineados, uma superfície ilimitada ao pensamento e exposição carnal da imaginação. Superfície lisa, retilínea, apta a medir sensações, sentimentos, desejos, constâncias e inconstâncias, ou melhor, a possibilidade de estancar o escrito, o caótico, o turbulento, intempestivo que se constitui num plano de composições. Compor uma escrita, uma imagem, um recorte no caos, um tempo feito em palavras e transcrito numa estrutura sensível. $\mathrm{O}$ pensamento cria.

A arte não se enquadra nos limites de uma forma, nem segue uma única direção. Insere-se no incorpóreo, no paradoxal, prefere à superfície sensível a profundidade inerte, a turbulência, a intensidade caótica. Não se associa ao tempo cronológico dissocia o tempo do passado, presente e futuro, constrói outras temporalidades. Afirma novidades ao produzir diferenças.

O ato de criar envolve pensar o não pensado, propor o que ainda não foi proposto, não significar, nem acreditar somente na reflexão, tampouco afirmar dicotomias entre teoria e prática. Criar envolve estabelecer correspondências, inventar um novo tempo, propor linhas e segmentos para mudar o dogma educacional e viver experiências. A arte não projeta nem faz dela um meio para se atingir um fim, seu fim é a vida.

Por meio da língua escrita foi possível criar um processo de ruptura entre a certeza da academia e a potência da construção artística. Envolto pelas sensações de um tex to que invade a psique dos estudantes ocorreu o processo de criação de objetos gráfico-visuais em sua maioria abordando tensões dolorosas, impressões infelizes, desejos abandonados, medos e anseios de um mundo que se desdobra por inseguranças.

Entre a audição e a sintaxe, surge a imagem e sua incipiente potência de criar realidades, traçar outros mundos, formar saberes. Letras, palavras, ortografias, gramáticas, contingência do mundo da escrita, um corpo de dados que serve a compreensão. Cor, tom, linha, ponto, textura, proporção. Ousadia, simetria, reiteração, ênfase. Pintura, escultura, fotografia, arquitetura, colagem, desenhos. Experiências em artes visuais. 


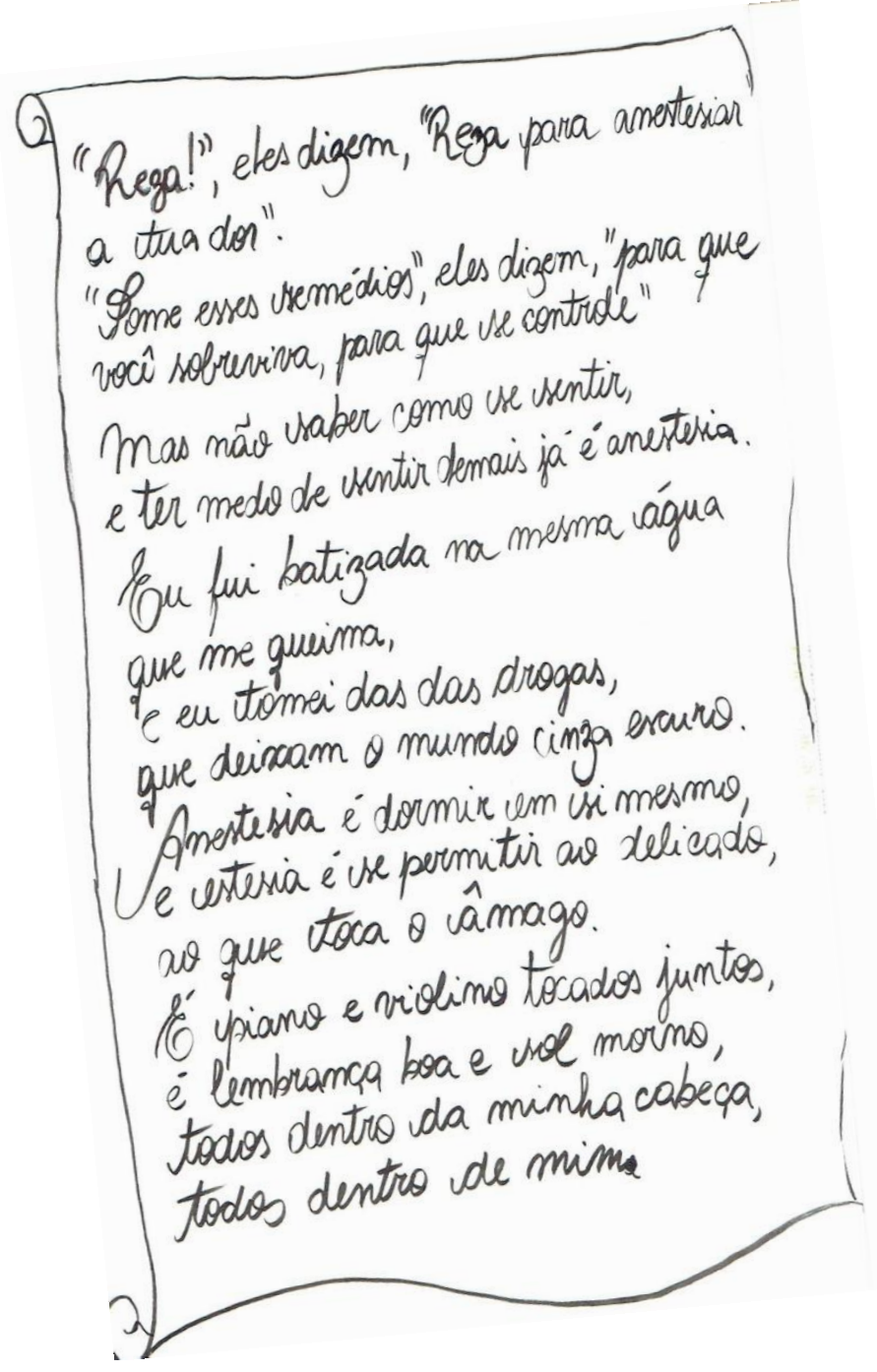

Figura 31: Estudante K - objeto gráfico-visual Fonte: autora

Neste processo de aprendizagem como professora-artista-pesquisadora foi possível mudar o foco da lente e ver as artes visuais como potência para o pensamento, a criação e o ato de deslocar-se da representação. Compor processos subjetivos a partir de atravessamentos sensíveis.

Criar, não é aprisionar aprendizagens, invalidar a experiência ou produzir categorias. É preciso escapar da necessidade de reconhecer, delinear, isolar, designar. Uma aula que sai do modelo da escrita, do caderno, texto, quadro branco e silêncio, e tenta introduzir o cotidiano, os desejos, paixões, anseios, interesses, impressões e aprendizagens, ao misturar imagens, tintas, corpos e produzir pensamentos, numa abertura ao caos, que se inventa e se reinventa com a intenção de provocar sensações estésicas.

Os movimentos de aprendizagem registrados nos discursos descritos neste artigo apontam o componente curricular de artes visuais como um artifício à compreensão de cores, 
formas, estilos, estratégias técnicas que produzem sensações de estesia, todavia promovem uma ruptura com o clichê ao vincular-se à experiência e devolver a imaginação que a sociedade nos usurpa. A experiência não ocorre no vácuo, na indiferença, em um objeto, mas sim, em nosso corpo, em células, veias, nervos, vibrações.

A experiência envolve ciência, arte e filosofia, dilemas e transgressões, pensamentos, indagações, incertezas, medos e criações, reconhecimentos, acontecimentos, singularidades, a potência do ato de aprender, produzir metamorfoses, compor envolvimentos, experimentar desafios, produzir imagens aptas a investigar a vida e inventar novas formas de viver.

\section{Referências}

ARCHER, Michael. Arte Contemporânea. Uma História Concisa. Trad. Alexandre Krug, Valter Lellis Siqueira. 2a ed. São Paulo: Editora WMF Martins Fontes, 2013.

DELEUZE, Gilles. Francis Bacon: Lógica da Sensação. Trad. Roberto Machado (coordenador, et al.). Rio de Janeiro: Zahar, 2007.

DELEUZE, Gilles; GUATTARI, Félix. O que é Filosofia? Trad. Bento Prado Jr. e Alberto Alonso Muñoz. $3^{\text {a }}$ ed. São Paulo: Editora 34, 2010.

DIAS, Belidson; IRWIN, Rita L. Pesquisa Educacional Baseada em Arte: A/r/tografia (org.). Santa Maria: Ed. da UFSM, 2013.

LARROSA, Jorge. Notas sobre a Experiência e o saber de Experiência. In: Revista Brasileira de Educação. n 19. Jan/Fev/Mar/Abr, 2002. p. 20-28.

LARROSA, Jorge. Experiência e Alteridade em Educação. In: Revista Reflexão e Ação. Santa Cruz do Sul, v. 19, n 2, jul/dez 2011. p. 04-27.

LANDOWSKI, Eric. Para uma Semiótica Sensível. In: Educação \& Realidade. 30 (2), jul/dez 2005, p. 93-106.

MARTINS, Mirian Celeste; PISCOSQUE, Gisa (org.). Mediação Cultural para Professores Andarilhos da Cultura. $2^{\text {a }}$ ed. São Paulo: Intermeios, 2012.

MASSCHEIN, Jan; SIMONS, Maarten. Em defesa da escola. Uma questão pública. Trad. Cristina Antunes. $2^{\circ}$ ed. $1^{\circ}$ reimp. Belo Horizonte: Autêntica Editora, 2015.

PELBART, Peter Pál. O corpo do Informe. In: GREINER, Christine; AMORIM, Claudia (orgs.). Leituras do Corpo. São Paulo: Annablume, 2003. p.67-76.

ROSENFIELD, Kathrin H. Estética. Rio de Janeiro: Jorge Zahar Ed., 2006.

SERRES, Michel. Os Cinco Sentidos. Filosofia dos corpos misturados. Trad. Eloá Jacobina. Rio de Janeiro: Bertrand Brasil, 2001. 
SERRES, Michel. Variações Sobre o Corpo. Trad. Edgard de Assis Carvalho; Mariza Perassi Bosco. Rio de Janeiro: Bertrand Brasil, 2004.

TOLSTÓI, Leon. O que é Arte? A polêmica visão do autor de Guerra e Paz. Trad. Bete Torii. 2. ed. Rio de Janeiro: Nova Fronteira, 2016. 